\title{
Enhanced Performance of Supercritical Fluid Foaming of Natural-Based Polymers by Deep Eutectic Solvents
}

\author{
Marta Martins, Ivo M. Aroso, Rui L. Reis, and Ana Rita C. Duarte \\ 3B's Research Group - Biomaterials, Biodegradable and Biomimetic, University of Minho, Headquarters of the \\ European Institute of Excellence on Tissue Engineering and Regenerative Medicine, Avepark 4806-909 Taipas, \\ Guimarães, Portugal
}

ICVS/3B's PT Government Associated Laboratory, Braga/Guimarães, Portugal

Rita Craveiro and Alexandre Paiva

Dept. de Química, REQUIMTE/CQFB, Faculdade de Ciências e Tecnologia, Universidade Nova de Lisboa, 2829-516 Caparica, Portugal

DOI 10.1002/aic.14607

Published online in Wiley Online Library (wileyonlinelibrary.com)

\section{Significance}

Natural deep eutectic solvents (NADES) are defined as a mixture of two or more solid or liquid components, which at a particular composition present a high melting point depression becoming liquids at room temperature. NADES are constituted by natural molecules and fully represent the green chemistry principles. For these reasons, the authors believe that the submitted manuscript is a highly valuable contribution to the field of green chemistry and chemical engineering. For the first time, the possibility to use NADES as enhancers of supercritical fluid technology is revealed. (C) 2014 American Institute of Chemical Engineers AIChE J, 00: 000-000, 2014

Keywords: biomaterials, green engineering, polymer processing, supercritical processes

$\mathrm{N}$ atural deep eutectic solvents (NADES) are considered today a new generation solvents. NADES can be constituted by two or more natural primary metabolites, namely, amino acids, organic acids, sugars, or choline derivatives. In this work, we evaluate the possibility of doping a natural-based polymer, particularly a blend of starch and poly- $\varepsilon$-carolactone (SPCL) with different NADES for enhanced processing. The results suggest that NADES may have a plasticizing effect on the polymer matrix. Samples of the NADES-doped polymer were foamed in supercritical carbon dioxide at 200 bar and $40^{\circ} \mathrm{C}$ for $2 \mathrm{~h}$. Results have shown that, despite an increase in porosity for all samples, it is highly depended on the NADES used. An increase in porosity for up to $52 \%$ was observed in the case of polymer doped with choline chloride-sucrose $(1: 1)$. This work

\footnotetext{
Correspondence concerning this article should be addressed to A. R. C. Duarte at aduarte@dep.uminho.pt.

(C) 2014 American Institute of Chemical Engineers
}

developed demonstrated the high potential of NADES as enhancers of the supercritical fluid foaming.

NADES have been reported to be the next generation of green solvents with the ability to replace ionic liquids (IL's) in some applications. For more than two decades, ionic liquids have been seen as green solvents for the future. Nonetheless, their applicability at large scales is still hindered by the lack of ecological and toxicological studies. Deep eutectic solvents (DES) are by definition a mixture of two or more organic compounds, which at a particular molar composition present a significant depression on their melting point, compared to the individual components. This depression may lead to the formation of liquid mixtures at room temperature. When these mixtures are composed by primary metabolites, such as amino acids, organic acids, choline derivatives, or sugars, DES are known as NADES. ${ }^{1-4}$

NADES have been reported to have applications in different research fields; however, the number of applications explored is still scarce due to the poor knowledge on the fundamental properties of these systems. ${ }^{5}$ Biocatalysis was one of the first reported applications of DES when Gill and 
Table 1. NADES Prepared and Water Content

\begin{tabular}{llcc}
\hline \multicolumn{3}{c}{ NADES } \\
\hline Component \#1 & Component \#2 & $\begin{array}{c}\text { Molar } \\
\text { Ratio }\end{array}$ & $\begin{array}{c}\text { Water Content } \\
\text { (wt \%) }\end{array}$ \\
\hline Glucose & CA & $1: 1$ & 8.2 \\
$\mathrm{ChCl}$ & Sucrose & $1: 1$ & 6.4 \\
$\mathrm{ChCl}$ & CA & $1: 1$ & 7.7 \\
$\mathrm{ChCl}$ & Xylose & $2: 1$ & 7.0 \\
$\mathrm{TA}$ & Glucose & $1: 1$ & 7.5 \\
$\mathrm{ChCl}$ & Xylose & $3: 1$ & 5.6 \\
$\mathrm{ChCl}$ & Sucrose & $4: 1$ & 8.1 \\
$\mathrm{CA}$ & Sucrose & $1: 1$ & 6.4 \\
\hline
\end{tabular}

$\mathrm{ChCl}$, choline chloride; $\mathrm{CA}$, citric acid; $\mathrm{TA}$, Tartaric acid.

Vulfson demonstrated that enzymes are able to retain their activity in eutectic mixtures proving a more suitable media than conventional organic solvents. ${ }^{6}$ NADES can also have an important role as green solvents for electrochemistry ${ }^{7}$ and extraction. ${ }^{8}$ In the biomedical or pharmaceutical field, the possibility to prepare drug delivery systems was reported by Stott et al. who describe the preparation of a bioactive eutectic system based on an anti-inflammatory agent, ibuprofen, for transdermal drug delivery. ${ }^{9}$ Other authors report the rheological behavior of bioactive eutectic mixtures for percutaneous delivery. ${ }^{10}$

In this work, we investigate the possibility of NADES to act as plasticizing agents enhancing the supercritical foaming of natural-based polymers. Supercritical fluid technology is an established technology that has received the generally regarded as safe status and has opened many possibilities for processing and development of new materials in a wide range of applications. In the pharmaceutical and biomedical field, the number of techniques developed is continuously increasing as the limitations and drawbacks of conventional existing technologies can be overcome to some extent. ${ }^{11,12}$ The preparation of lightweight porous materials is one example of these developments. In the gas foaming, the polymer is exposed to carbon dioxide at the saturation pressure and temperature, which plasticizes the polymer and reduces the glass transition temperature. Upon depressurization, thermodynamic instability causes supersaturation of the carbon dioxide dissolved in the polymeric matrix, and hence, nucleation of the cells occurs. The main requirement of the $\mathrm{CO}_{2}$-foaming process is that $\mathrm{CO}_{2}$ can be dissolved in a sufficient amount in the polymer. This excludes for instance, the use of polymers which have a very low affinity for $\mathrm{CO}_{2},{ }^{13-15}$ as is the case of polymers with high crystallinity or high glass transition temperatures. This technique is more commonly applied to amorphous polymers. These limitations compromise processing of natural-based polymers using this technique.

In an attempt to overcome this drawback, the use of plasticizing agents has been reported. These can improve the foaming ability by either promoting the decrease on glass and melting point of the polymers or enhancing carbon dioxide solubility in the matrix. Plasticizing agents are low molecular weight compounds that are able to decrease the intermolecular forces between the polymer chains, improving the flexibility of the polymer network. Martins et al. have reported the possibility to use ionic liquids as plasticizing agents of semicrystalline polymers, namely doping blends of starch and poly-lactic acid with 1-butyl-3-methylimidazolium chloride $([\mathrm{BMIM}] \mathrm{Cl}) .{ }^{16}$ Sankri et al. report the use of the same ionic liquid for the preparation of thermoplastic starch. ${ }^{17}$ The use of 1-butyl-3-methylimidazolium acetate ([BMIM]Ac) as plasticizing agent for a starch-based polymer has also been studied in the literature. ${ }^{18,19}$

The interest in natural-based polymers comes from the fact that they are renewable and degradable products, biocompatible, nontoxic, and present inherent biological activity. They are further seen as safe and green alternatives for traditional plastics, and find applications in areas ranging from biomedicine and pharmaceutical to areas as distinct as electronics. Their major drawback is though related to their low processability. ${ }^{20}$

In this work, we evaluate the ability of different NADES to enhance supercritical carbon dioxide foaming process and promote the preparation of three-dimensional (3-D) porous structures. The NADES tested are listed in Table 1. NADES were prepared following the work reported by Dai et al. ${ }^{1}$ The two components were dissolved in water in the appropriate molar ratio and the water was evaporated under vacuum, in a rotary evaporator at $50^{\circ} \mathrm{C}$, until a clear viscous solution was obtained. NADES are highly hygroscopic solutions, and the presence of water has to be controlled as water may also act as a plasticizing agent. The percentage of water present in the NADES prepared was determined by KarlFischer titration and the results are presented in Table 1.

SPCL blends dopped with $10 \mathrm{wt} \%$ of NADES were prepared by compression moulding using a Moore hydraulic press (UK) at $80^{\circ} \mathrm{C}$ and $8 \mathrm{MPa}$ for $15 \mathrm{~min}$. Thermal degradation at this temperature is unlikely to occur as confirmed by the thermal degradation analysis, particularly by differential scanning calorimetry, of the different NADES used (Craveiro et al., Submitted).

According to the definition of a plasticizer, the plasticizing ability is characterized among other features by the differences in the mechanical properties of the blends. We evaluated the mechanical properties of the different polymer-NADES systems in the tensile mode, using specimens of $60 \mathrm{~mm}$ in length, $1 \mathrm{~mm}$ width, and $3 \mathrm{~mm}$ thickness. The load was placed

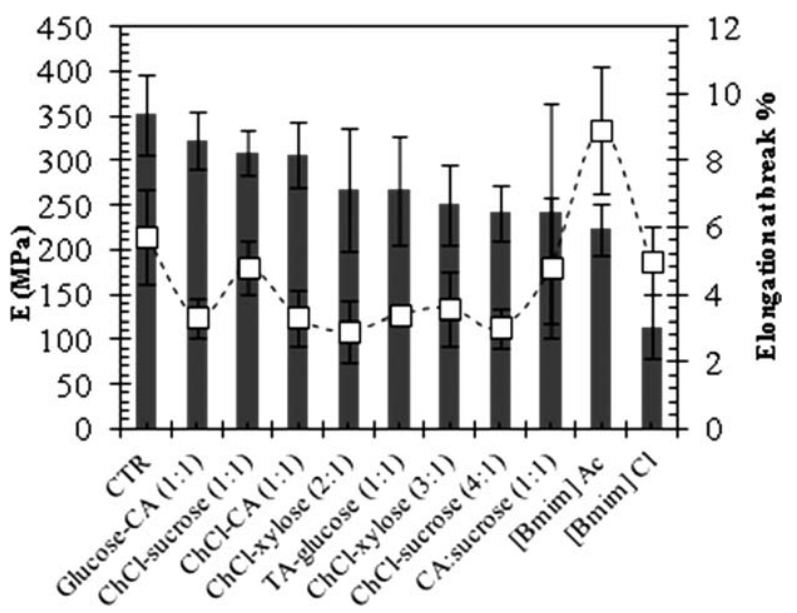

Figure 1. Mechanical properties of SPCL blends.

Young modulus $(E)$ represented with bars on primary axis and elongation at break in bullets. CTR is a SPCL control sample. 

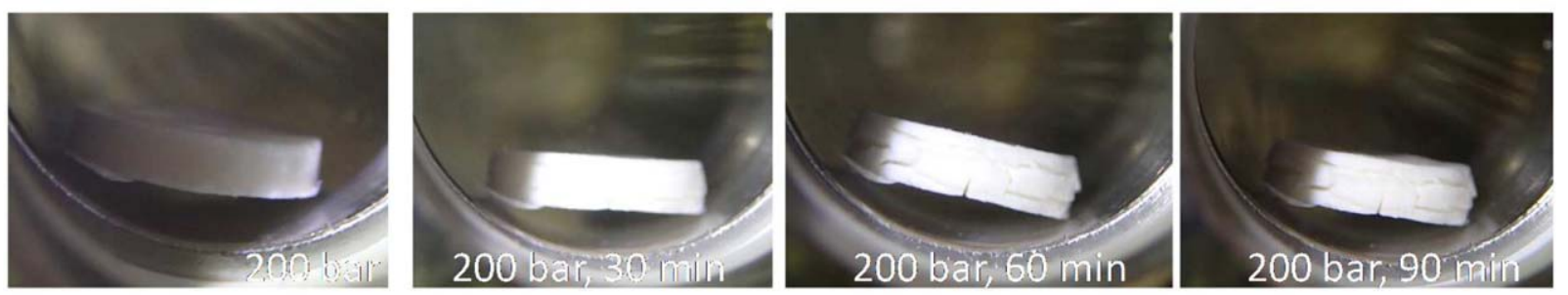

Depressurization
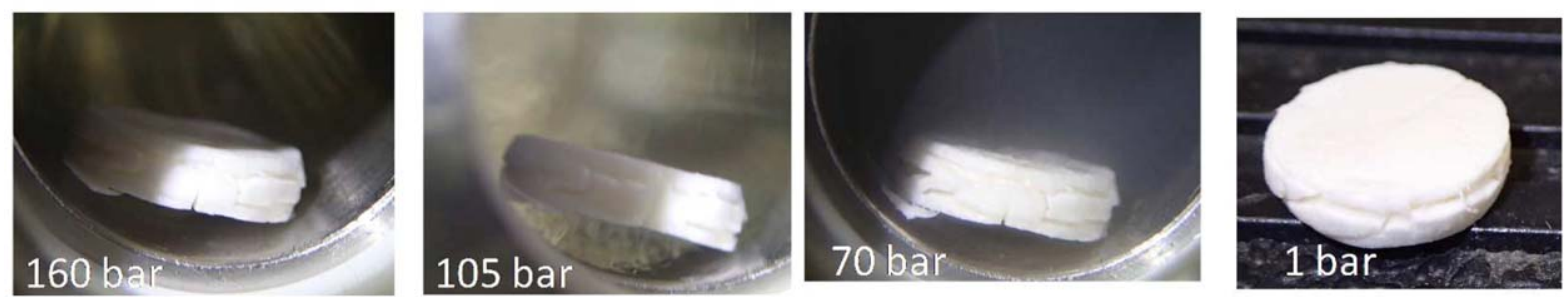

Figure 2. Effect of pressurization and depressurization on foaming process for the polymer (SPCL).

[Color figure can be viewed in the online issue, which is available at wileyonlinelibrary.com.]

midway between the supports with a span $(L)$ of $30 \mathrm{~mm}$. The crosshead speed was $1: 5 \mathrm{~mm} \mathrm{~min}^{-1}$. For each condition, the specimens were loaded until core break. The results presented are the average of at least three measurements.

The Young modulus and the elongation at break determined for the different samples are presented in Figure 1. For comparison, the results of SPLC dopped with two butylimidazolium ionic liquids, 1-butyl-3-methylimidazolium acetate ([BMIM]Ac), and 1-butyl-3-methylimidazolium chloride $([\mathrm{BMIM}] \mathrm{Cl})$ studied in a previous work are presented. ${ }^{18,19}$

The mechanical response of the SPCL blends studied suggests that the presence of NADES lowers the Young modulus and the elongation at break, providing cues that NADES may increase chain mobility and promote a plasticizing effect on the polymer matrix, similarly to what was observed with ionic liquids. Nonetheless, this effect is not always so significant as in the case of $[\mathrm{BMIM}] \mathrm{Cl}$. The increased mobility of the polymeric chains is a result of the interactions of polymers with the plasticizing agent and will affect the mechanical properties of the matrices. The addition of a plasticizer provides large intermolecular space between the chains of the polymers reducing the energy required for polymeric chain movement, therefore decreasing the Young modulus and the elongation at break. ${ }^{21,22}$

After compression moulding, the samples were foamed in the presence of supercritical carbon dioxide. The samples were loaded in a high pressure vessel, at $40^{\circ} \mathrm{C}$ and pressurized with carbon dioxide at $20.0 \mathrm{MPa}$, for $2 \mathrm{~h}$. The pressuration step takes about $10 \mathrm{~min}$. The system is then depressurized at a rate of $0.67 \mathrm{MPa} / \mathrm{min}$. Saphire windows allow the visualization of the foaming process.

Optical images of the foaming process after predetermined periods of time, during the pressurization and

\section{Pressurization}
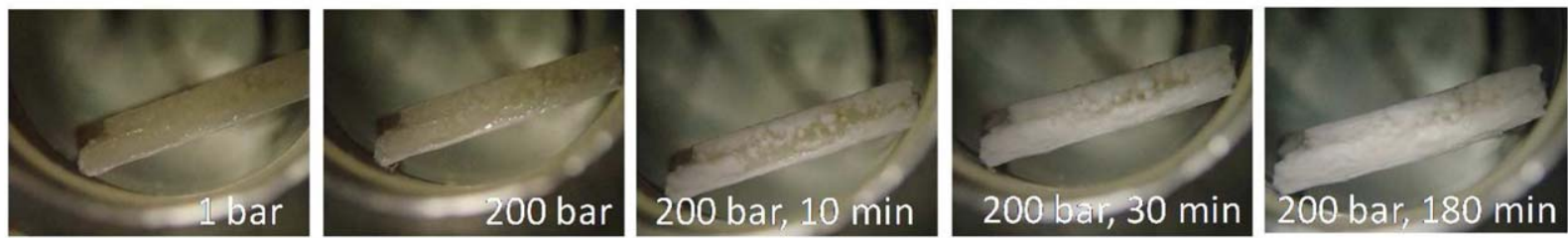

Depressurization
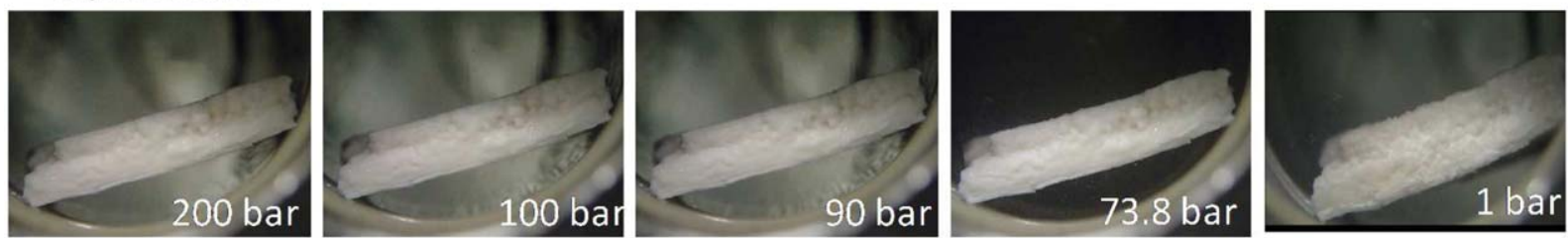

Figure 3. Effect of pressurization and depressurization on foaming process for the system SPCL + TA-glucose (1:1).

[Color figure can be viewed in the online issue, which is available at wileyonlinelibrary.com.] 
depressurization stages are presented in Figures 2 and 3. Figure 2 presents the foaming process for the polymer SPLC alone and Figure 3 presents the different stages of the foaming for the system SPCL + TA-glucose (1:1). As it can be observed from Figure 2, the SPCL sample after foaming presents cracks and it is not homogeneously foamed.

Regarding the SPCL + TA-glucose (1:1) sample, the differences between the samples can be observed as soon as the samples are pressurized in the vessel and the extent of foaming is dependent on the nature of the NADES dispersed in the blend. In the first images, it is clearly visible the diffusion of carbon dioxide into the bulk of the sample, which also corresponds to a slight change in color and swelling of the sample. The critical parameters in supercritical $\mathrm{CO}_{2}$ foaming are the concentration of $\mathrm{CO}_{2}$ in the polymer and the rate of $\mathrm{CO}_{2}$ depressurization. ${ }^{23}$ These are closely related to the solubility of $\mathrm{CO}_{2}$ in the polymers, but in this case they are also probably related with the solubility of carbon dioxide in NADES, however, this has not yet been reported. The rate of depressurization $\delta \mathrm{P} / \delta \mathrm{t}$ and polymer relaxation is not independent processes, and may contribute to differences in the foams obtained. In this work, the depressurization rate was controlled so that it allows the nucleation of pores and their growth without coalescence. This is evidenced by the images on Figure 3, in which during the depressurization process the matrix does not undergo extensive swelling. It can be hypothesized that the swelling occurs during the diffusion of $\mathrm{CO}_{2}$ into the matrix at high pressure and thus dependent of time, temperature, and pressure, while the 3-D internal structure is created during depressurization and nucleation, hence mainly dependent on depressurization rate.

Cross-section of the samples were observed by scanning electron microscopy (SEM) and were analyzed by microcomputed tomography (micro-CT) which allows the determination of the morphological parameters that characterize the samples. Figure 4 presents the cross-sections of the SPCL foamed structures with the different NADES, by SEM and Micro-CT. From these images, it is possible to visualize that the porosity of SPCL foamed samples is highly dependent on the NADES used. In case of polymer blended with $\mathrm{ChCl}$ :sucrose (1:1) and $\mathrm{ChCl}$ :CA (1:1), the foamed structures present large open pores. Micro-CT provides visual information on the three sections of the matrices. The results obtained show the homogeneity of the foamed structures in all three axes. Moreover, the SEM images revealed the interconnectivity of the pores and a mean pore size which is in agreement with micro-CT analysis.

The microscopy analysis illustrates the great effect of NADES on the foaming of semicrystalline natural-based polymer SPCL. This effect can be quantified in terms of the morphological parameters, such as porosity, mean pore size, and interconnectivity of the structures.

The morphological parameters were determined by the analysis of two-dimensional (2-D) images of the matrices using CT analyzer software (version 1.5, SkyScan). 2-D cross-sections of the structure were visualized using DataViewer software (version 1.4.4 64-bit, SkyScan) and the 3-D reconstructions were built using CTVox software (version 2.3.0 r810, SkyScan). A summary of the results obtained is presented in Table 2 .
From the results obtained, an increase in porosity up to $52 \%$ in the case of polymer dopped with ChCl-sucrose $(1: 1)$ was observed, meaning that NADES have higher potential to

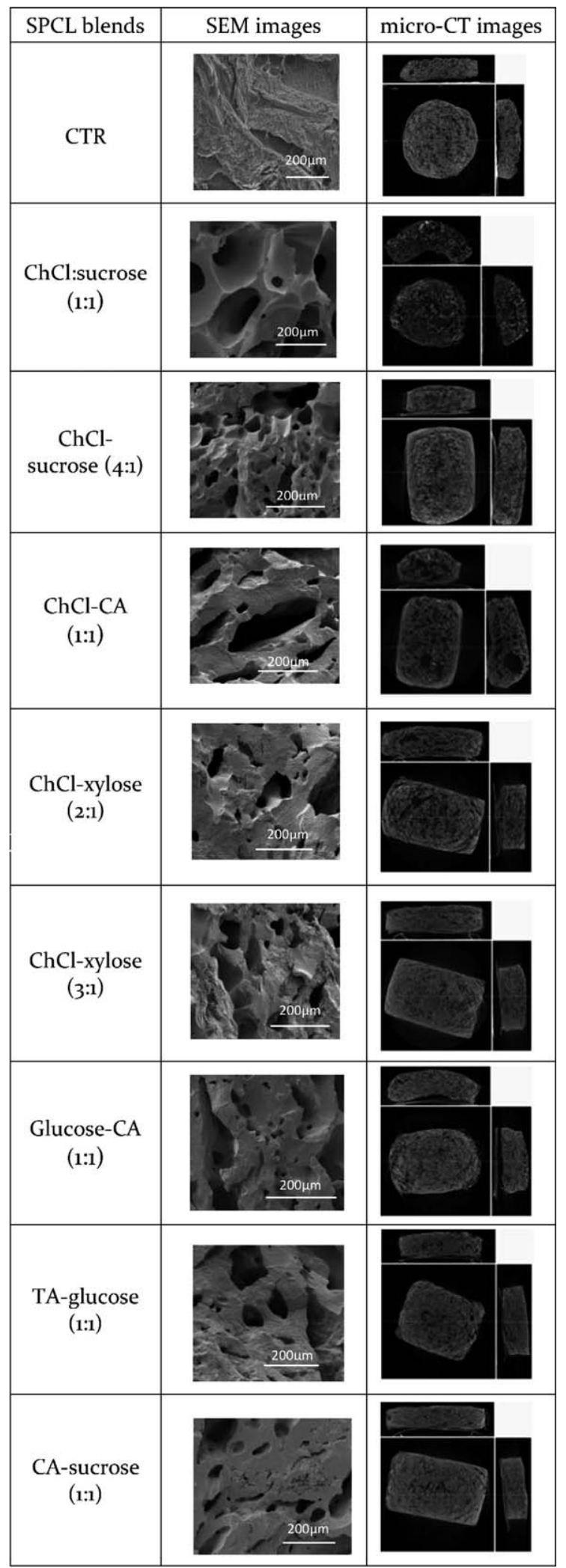

Figure 4. SEM and micro-CT images of materials prepared after foaming process. 
Table 2. Morphological Parameters [Porosity, Mean Pore Size, and Interconnectivity (IC)] of SPCL Foamed Samples

\begin{tabular}{lrcr}
\hline SPCL Blends & Porosity $(\%)$ & Mean Pore Size $(\mu \mathrm{m})$ & \multicolumn{1}{c}{ IC $(\%)$} \\
\hline CTR & $4.1 \pm 0.9$ & - & - \\
ChCl-sucrose $(1: 1)$ & $51.7 \pm 6.0$ & $209 \pm 35$ & $59.5 \pm 1.9$ \\
ChCl-sucrose $(4: 1)$ & $8.2 \pm 1.3$ & $129 \pm 4.9$ & $5.0 \pm 1.0$ \\
ChCl-CA (1:1) & $42.8 \pm 1.9$ & $350 \pm 21$ & $34.6 \pm 4.9$ \\
ChCl-xylose (2:1) & $21.5 \pm 3.0$ & $243 \pm 54$ & $13.5 \pm 7.3$ \\
ChCl-xylose (3:1) & $5.0 \pm 1.0$ & $111 \pm 3$ & $3 \pm 1.0$ \\
Glucose-CA (1:1) & $5.3 \pm 0.9$ & $108 \pm 3$ & $5.8 \pm 1.8$ \\
TA-glucose (1:1) & $14.9 \pm 2.4$ & $182 \pm 3$ & $9.3 \pm 1.5$ \\
CA-sucrose $(1: 1)$ & $4.7 \pm 1.1$ & $166 \pm 39$ & $7.2 \pm 3.5$ \\
\hline
\end{tabular}

CTR is a SPCL Control Sample.

promote gas foaming when compared with conventional ionic liquids already studied such as [BMIM]Ac. The morphology of SPCL structures dopped with $10 \%$ of [BMIM]Ac using different soaking times (30 min up to $3 \mathrm{~h}$ ) was evaluated by Duarte et al. ${ }^{18}$ which reported, under the same operating conditions, a maximum of $40 \%$ porosity. Conversely, the SPCL blend foamed without presence of NADES, showed low values of porosity.

Another feature which is important to discuss is the possible plasticizing effect of water on these structures. Concerning the results of water content of the NADES used (Table 1) and the foaming extension observed (Table 2), it seems that water does seem to have a great effect as a plasticizing agent. This fact is well demonstrated in the case of glucose-CA (1:1) which, although having a higher content of water percentage the extension of foaming on SPCL blend is low, demonstrating that the in the foaming process the NADES effect prevail over the effect of water. $\mathrm{Li}$ and coworkers determined the solubility of carbon dioxide in aqueous DES systems in which the water concentration varied between 20 and $80 \%$. In general, they observed that high concentrations of water have an antisolvent effect, decreasing the solubility of carbon dioxide in the mixture. ${ }^{24}$ This is in agreement with the results obtained in this work, where the presence of water seemed to be detrimental to the foaming process.

Few articles report, however, the solubility of carbon dioxide in eutectic mixtures. $\mathrm{Li}$ and coworkers have determined the solubility of carbon dioxide in an eutectic mixture of choline chloride and glycerol, reporting a solubility of carbon dioxide in the mixture of approximately $3 \mathrm{~m}_{\mathrm{CO}_{2}} /\left(\mathrm{mol}_{\mathrm{CO}_{2}}\right.$ $\mathrm{kg}^{-1}$ ) at $6.0 \mathrm{MPa}$ and $40^{\circ} \mathrm{C}$. Their findings also indicate that the solubility of $\mathrm{CO}_{2}$ in DES follows a linear relationship with pressure, but it is inversely proportional to the temperature. These trends are typical and have already been reported to carbon dioxide:ionic liquid systems. ${ }^{25}$ The systems presented in our work have so far not been reported in the literature, but a rough comparison can be made with the systems prepared with ionic liquids. Our previous work on the preparation of porous matrices dopped with 1-butyl-3methylimidazolium chloride has demonstrated that the extent of foaming is related with the sorption degree of the polymers which is greatly influenced by the solubility of carbon dioxide in the ionic liquid. ${ }^{16}$ In comparison with the systems prepared with ionic liquids, NADES present major advantages. NADES have potentially lower toxicity than the ILs that present higher relevance for biomedical or pharmaceutical applications. Moreover, in some cases, better results were obtained for NADES than with ILs.

The results presented in this work demonstrate the possibility to use of a novel generation of green solvents as polymers plasticizing agents for the development of 3-D porous architectures. The preparation of porous, light weight materials may have applications in a wide variety of scientific fields. Nonetheless, the major goal of the present work is to provide cues for future developments, particularly the development of new bioactive materials using active NADES for tissue engineering and/or drug delivery applications.

\section{Acknowledgments}

The research leading to these results has received funding from Fundação da Ciência e Tecnologia (FCT) through the project ENIGMAPTDC/EQU-EPR/121491/2010 and the project PEst-C/EQB/LA0006/ 2013. The funding from the European Union's Seventh Framework Programme (FP7/2007-2013) under grant agreement $\mathrm{n}^{\circ}$ REGPOT-CT2012316331-POLARIS and from Project "Novel smart and biomimetic materials for innovative regenerative medicine approaches (Ref.: RL1 ABMR - NORTE-01-0124-FEDER-000016)" cofinanced by North Portugal Regional Operational Programme (ON.2 - O Novo Norte), under the National Strategic Reference Framework (NSRF), through the European Regional Development Fund (ERDF) and FEDER are also acknowledged. Marta Martins, Rita Craveiro and Alexandre Paiva are grateful for financial support from Fundação da Ciência e Tecnologia (FCT) through the grants BIM/PTDC/EQU-EPR/121491/2010/ENIGMA and SFRH/BPD/44946/2008.

\section{Literature Cited}

1. Dai YT, van Spronsen J, Witkamp GJ, Verpoorte R, Choi YH. Natural deep eutectic solvents as new potential media for green technology. Anal Chim Acta. 2013;766: 61-68.

2. Paiva A, Craveiro R, Aroso I, Martins M, Reis RL, Duarte ARC. Natural deep eutectic solvents - solvents for the 21st century. ACS Sustain Chem Eng. 2014;2: 1063-1071.

3. Francisco M, van den Bruinhorst A, Kroon MC. Lowtransition-temperature mixtures (LTTMs): a new generation of designer solvents. Angew Chem Int Ed. 2013; 52(11):3074-3085.

4. Choi YH, van Spronsen J, Dai YT, Verberne M, Hollmann F, Arends IW, Witkamp GJ, Verpoorte R. Are natural deep eutectic solvents the missing link in understanding cellular metabolism and physiology? Plant Physiol. 2011;156(4):1701-1705.

5. Zhang QH, Vigier KD, Royer S, Jerome F. Deep eutectic solvents: syntheses, properties and applications. Chem Soc Rev. 2012;41(21):7108-7146.

6. Gill I, Vulfson E. Enzymatic catalysis in heterogeneous eutectic mixtures of substrates. Trends Biotechnol. 1994; 12(4):118-122.

7. Nkuku CA, LeSuer RJ. Electrochemistry in deep eutectic solvents. J Phys Chem B. 2007;111(46):13271-13277.

8. Dai YT, Witkamp GJ, Verpoorte R, Choi YH. Natural deep eutectic solvents as a new extraction media for phenolic metabolites in Carthamus tinctorius L. Anal Chem. 2013;85(13):6272-6278.

9. Stott PW, Williams AC, Barry BW. Transdermal delivery from eutectic systems: enhanced permeation of a 
model drug, ibuprofen. J Control Release. 1998;50(1-3): 297-308.

10. Woolfson AD, Malcolm RK, Campbell K, Jones DS, Russell JA. Rheological, mechanical and membrane penetration properties of novel dual drug systems for percutaneous delivery. J Control Release. 2000;67(2-3):395408.

11. Duarte ARC, Mano JF, Reis RL. Perspectives on: supercritical fluid technology for 3D tissue engineering scaffold applications. J Bioact Compat Polym. 2009;24(4): 385-400.

12. Duarte ARC, Mano JF, Reis RL. Supercritical fluids in biomedical and tissue engineering applications: a review. Int Mater Rev. 2009;54(4):214-222.

13. Cooper AI. Polymer synthesis and processing using supercritical carbon dioxide. J Mater Chem. 2000;10(2): 207-234.

14. Cooper AI. Porous materials and supercritical fluids. $A d v$ Mater. 2003;15(13):1049-1059.

15. Jacobs LJM, Kemmere MF, Keurentjes JTF. Sustainable polymer foaming using high pressure carbon dioxide: a review on fundamentals, processes and applications. Green Chem. 2008;10(7):731-738.

16. Martins M, Craveiro R, Paiva A, Duarte ARC, Reis RL. Supercritical fluid processing of natural based polymers doped with ionic liquids. Chem Eng J. 2014;241:122130.

17. Sankri A, Arhaliass A, Dez I, Gaumontb AC, Grohensc Y, Lourdind D, Pillinc I, Rolland-Sabatéd A, Leroy E. Thermoplastic starch plasticized by an ionic liquid. Carbohydr Polym. 2010;82(2):256-263.

18. Duarte ARC, Silva SS, Mano JF, Reis RL. Ionic liquids as foaming agents of semi-crystalline natural-based polymers. Green Chem. 2012;14(7):1949-1955.

19. Craveiro R, Martins M, Santos GB, Correia N, Dionísio M, Barreiros S, Duarte ARC, Reisbc RL, Paiva A.
Starch-based polymer-IL composites formed by compression moulding and supercritical fluid foaming for selfsupported conductive material. RSC Adv. 2014;4:1716117170.

20. Mano JF, Silva GA, Azevedo HS, Malafaya PB, Sousa RA, Silva SS, Boesel LF, Oliveira JM, Santos TC, Marques AP, Neves NM, Reis RL. Natural origin biodegradable systems in tissue engineering and regenerative medicine: present status and some moving trends. $J R$ Soc Interface. 2007;4(17):999-1030.

21. Shamsuri AA, Daik R. Plasticizing effect of choline chloride/urea eutectic-based ionic liquid on physicochemical properties of agarose films. Bioresources. 2012; 7(4):4760-4775.

22. Choi SY, Rodriguez H, Mirjafari A, Gilpin DF, McGrath S, Malcolm KR, Tunney MM, Rogerscf RD, McNally T. Dual functional ionic liquids as plasticisers and antimicrobial agents for medical polymers. Green Chem. 2011; 13(6):1527-1535.

23. Tai HY, Mather ML, Howard D, Wang W, White LJ, Crowe JA, Morgan SP, Chandra A, Williams DJ, Howdle SM, Shakesheff KM. Control of pore size and structure of tissue engineering scaffolds produced by supercritical fluid processing. Eur Cell Mater. 2007;14: 64-76.

24. Lin CM, Leron RB, Caparanga AR, Li MH. Henry's constant of carbon dioxide-aqueous deep eutectic solvent (choline chloride/ethylene glycol, choline chloride/glycerol, choline chloride/malonic acid) systems. J Chem Thermodyn. 2014;68:216-220.

25. Leron RB, Li MH. Solubility of carbon dioxide in a eutectic mixture of choline chloride and glycerol at moderate pressures. J Chem Thermodyn. 2013;57:131-136.

Manuscript received June 11, 2014 